$$
\mathrm{OH} 338
$$


192 


\title{
A METHOD OF PREPARING FISHES FOR MUSEUM AND EXHIBITION PURPOSES
}

\author{
* \\ By Dwight Franklin \\ American Museum of Natural History, New York City
}

\begin{abstract}
$*$
Models presented before the Fourth International Fishery Congress held at Washington, U. S. A., September 22 to 26, 1908 and awarded the prize of one hundred dollars in.gold offered by the American Museum of Natural History for the best method of preparing fishes for museum and exhibition purposes
\end{abstract}

BULLETIN OF THE BUREAU OF FISHERIES : : : : : VOL. XXVIII, P. 1353-1355

Document No. $723:: \quad: \quad: \quad: \quad: \quad: \quad: \quad: \quad: \quad: \quad: \quad: \quad: \quad$ : : Issued May, 1910 
$\cdots$ 

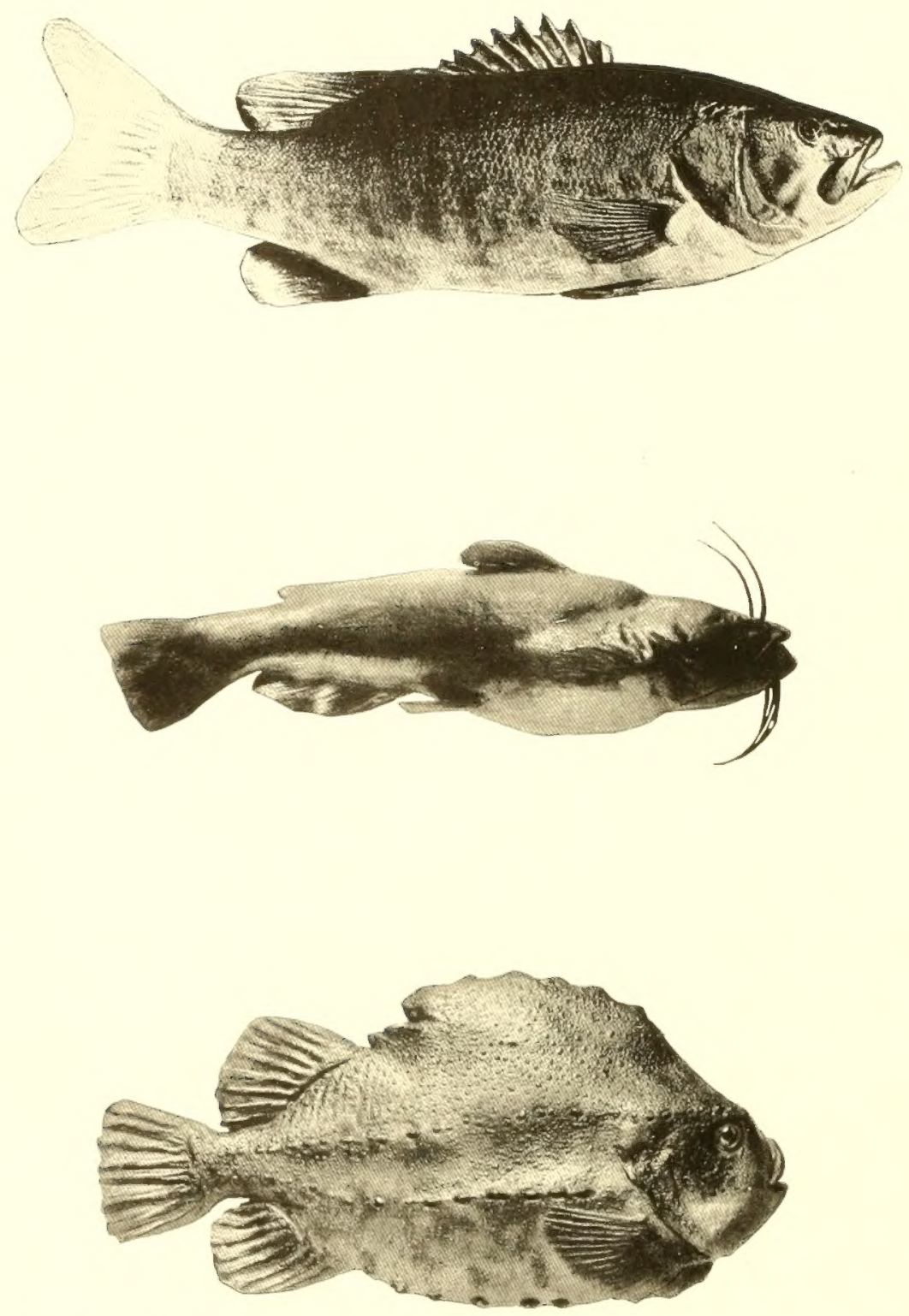


\title{
A METHOD OF PREPARING FISHES FOR MUSEUM AND EXHIBITION PURPOSES.
}

\author{
$3^{3}$ \\ By DUIGHT FRANKLIN, \\ American Muscum of Natural History, New York City.
}

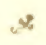

The preparation of fish for museum and exhibition purposes has always presented considerable difficulty. In most museums three methods of representation are in vogue, namely, by alcoholics, mounted skins, and plaster casts. The following are some of the commonly accepted objections to these methods: (I) Specimens preserved in any known liquid lose their color and give little idea of the living fish. (2) Fiew fish can be successfully mounted, as the soft parts about the head and fins shrivel and the skin becomes dry and opaque, so that no amount of skillful coloring can restore the original translucency. If the specimen is coated with wax the detail is lost, while the softness is only on the surface of the fish, not a part of it. (3) Plaster casts may reproduce the form perfectly, but all translucency is lost. If in the last method, however, a medium could be used which is itself soft and semitransparent, the result would prove more satisfactory. It has been found that wax answers this purpose admirably. It is easily handled, retains its form, and may be successfully colored.

The method used in making the specimens shown in the accompanying illustrations is as follows:

First remove the slime from the fish and pose the animal as desired. If a cast of one side only is desired the specimen may be backed up with clay.

Now pour plaster over the fish and allow it to harden thoroughly, after which the fish may be removed from the mold and laid aside.

As a third step soak the mold in hot water until it is saturated, then absorb the excess water from the surface.

Finally pour melted beeswax of the desired color into and out of the mold until a thick coating of wax is formed, then allow it to cool. Before the wax has hardened wire hangers may be inserted.

When the cast is cold carefully chip off the plaster mold, point up the wax cast, if necessary, and there has been produced a lifelike reproduction of the fish, which needs only to be finished by being colored accurately.

Models prepared by this method are shown in plate CxLII. 


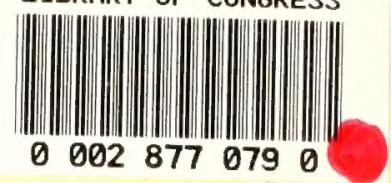




$$
F_{7}
$$


LIBRARY OF CONGRESS

|| || || |||||||||||||||||||||||||

|| || || || ||

Hollinger Corp. pH 8.5 